\title{
Acute flaccid paralysis associated with enterovirus D68 infection: a case report
}

\author{
Wilson YK Chan ${ }^{1,2}$ *, FHKAM (Paediatrics), Stella HY Chim², FHKAM (Paediatrics), Donald ML Tse ${ }^{3}$, FHKAM (Radiology), \\ PL Ho ${ }^{4}$, FHKAM (Pathology)
}

\author{
${ }^{1}$ Department of Paediatrics and Adolescent Medicine, Hong Kong Children's Hospital, Hong Kong \\ ${ }^{2}$ Department of Paediatrics and Adolescent Medicine, Queen Mary Hospital, Hong Kong \\ ${ }^{3}$ Department of Diagnostic Radiology, Queen Mary Hospital, and St Teresa's Hospital, Hong Kong \\ ${ }^{4}$ Department of Microbiology, Li Ka Shing Faculty of Medicine, The University of Hong Kong, Hong Kong
}

*Corresponding author: wykchan@hku.hk

Hong Kong Med J 2021;27:355-7

https://doi.org/10.12809/hkmj208931

\section{Case report}

In July 2017, a 28-month-old boy presented to a private outpatient clinic with a 2-day history of fever and coryzal symptoms (Table). He had enjoyed good past health and his family history was unremarkable. On clinical examination, he was noted to have respiratory distress and tachycardia. Plain radiograph of the chest (CXR) showed perihilar haziness but no consolidation. He was transferred to Queen Mary Hospital, Hong Kong, to exclude myocarditis in view of elevated serum troponin in blood taken in the private clinic. On admission, he was noted to have diffuse crepitations and wheeze suggestive of pneumonitis. Nebulised salbutamol, hypertonic saline, and intravenous cefotaxime were administered. Complete blood count revealed neutrophilia, normal liver and renal function, and normal creatine kinase level. Venous blood gas showed no acidosis. Troponin was high initially but then gradually normalised. Echocardiogram showed no features of myocarditis. Nasopharyngeal aspirate and throat swab test results were positive for enterovirus (EV)/rhinovirus ribonucleic acid (RNA) using reverse transcriptase-polymerase chain reaction (RT-PCR) detection method. EV71 RNA was not evident. Nasopharyngeal aspirate for mycoplasma, throat swab and blood culture were all negative. He then developed progressive respiratory distress with increased cough and high fever up to $40^{\circ} \mathrm{C}$ on day 7 of illness and CXR showed worsening of bilateral perihilar haziness. In view of the progressive respiratory failure, the child was admitted to the paediatric intensive care unit 2 days later (day 9).

On admission to paediatric intensive care unit, he was noted to have generalised muscle weakness with a weak voice and an inability to sit up. Gag reflex and jerks were preserved. He was then intubated and ventilated under sedation. On reassessment, chest auscultation revealed decreased air entry over the left side, corresponding to the left lower zone collapse evident on CXR. He was prescribed piperacillin- tazobactam and levofloxacin. On day 10, throat swab culture grew only commensals while endotracheal aspirate revealed scanty growth of alpha-haemolytic streptococci with negative fungal smear and culture, and RT-PCR identified EV/rhinovirus. Bronchoalveolar lavage was also performed but results were unremarkable: Pneumocystis jiroveci (carinii), smear and culture for bacteria, fungus and acid-fast bacilli, and RT-PCR for cytomegalovirus, herpes simplex virus, Mycoplasma, Legionella, were all negative. Urine culture was negative for Legionella antigen.

On day 11, the patient exhibited paradoxical breathing on weaning of sedation along with hypotonia and paralysis of four limbs. Urgent sagittal T2-weighted magnetic resonance imaging of spine (day 11) showed mild T2 hyperintensity with mild expansion within the central portion of the cervical cord from C3 to C6 (Fig). No intraspinal mass or collection could be seen. Neurology examination was performed on day 12 . Creatine kinase was normal and anti-acetylcholine receptor and antiaquaporin-4 were negative. Eye examination the following day showed no evidence of optic neuritis. Immunoglobulin $\mathrm{G}$ and immunoglobulin $\mathrm{M}$ of antigangliosides were all negative. Lumbar puncture revealed normal cerebrospinal fluid level of glucose and protein. Total cell count was $100 \times 10^{6} / \mathrm{L}$ with predominantly $(80 \%)$ neutrophils. Cerebrospinal fluid culture was negative for viruses, including $\mathrm{EV}$, herpes simplex virus or varicella-zoster virus. Cerebrospinal fluid levels of oligoclonal protein and immunoglobulin $G$ were unremarkable. The working diagnosis was transverse myelitis affecting cervical cord C3 to C6. He was prescribed pulse methylprednisolone $30 \mathrm{mg} / \mathrm{kg}$ for 5 days (day 12 to 16) followed by a tapering oral dose of prednisolone together with intravenous immunoglobulin $2 \mathrm{~g} / \mathrm{kg}$ over 2 days (day 16 and 17). He was also treated with therapeutic plasma exchange with 1.5 -times plasma volume for five courses over 2 weeks (day 22, 24, 26, 30,32 ). His condition gradually improved and he was extubated (day 47) after 38 days of invasive ventilation. 
TABLE. Timeline of clinical course, investigation results, treatment, and management of the index case

\begin{tabular}{|c|c|c|c|}
\hline $\begin{array}{l}\text { Day from } \\
\text { symptom } \\
\text { onset }\end{array}$ & Clinical manifestations & Investigation results & Treatment and management \\
\hline Day 1 & $\begin{array}{l}\text { - Fever and coryzal symptoms for } 2 \text { days at } \\
\text { GOPC in private hospital } \\
\text { - RD and tachycardia on exam }\end{array}$ & - CXR: perihilar haziness, no consolidation & \\
\hline Day 3 & $\begin{array}{l}\text { - Transferred and admitted to Queen Mary } \\
\text { - Hospital to rule out myocarditis } \\
\text { diffuse crepitations and wheeze } \\
\text { suggestive of pneumonitis }\end{array}$ & $\begin{array}{l}\text { - Initially elevated troponin, subsequently } \\
\text { normalised. ECHO: no signs of myocarditis } \\
\text { - } \text { CBC showed neutrophilia } \\
\text { - LRFT, CK, CK-MB and VBG normal } \\
\text { - NPA EV/RV RNA RT-PCR positive, EV71 RNA } \\
\text { not detected by RT-PCR } \\
\text { - NPA for mycoplasma, TS and blood culture } \\
\text { all negative } \\
\text { - EV-D68 RNA were detected by gene } \\
\text { sequencing subsequently on day } 30 \text { in NPA, } \\
\text { ETA and stool samples }\end{array}$ & $\begin{array}{l}\text { - Nebulised salbutamol and } \\
\text { nebulised hypertonic saline } \\
\text { - IV cefotaxime }\end{array}$ \\
\hline Day 7 & $\begin{array}{l}\text { - Progressive RD with increased cough, } \\
\text { swinging fever up to } 40^{\circ} \mathrm{C}\end{array}$ & - CXR: worsening of bilateral perihilar haziness & \\
\hline Day 9 & $\begin{array}{l}\text { - Admitted to PICU in view of progressive } \\
\text { respiratory failure }\end{array}$ & & \\
\hline Day 10 & $\begin{array}{l}\text { - Generalised muscle weakness, unable to } \\
\text { sit up, weak voice } \\
\text { - Gag reflex and jerks still present } \\
\text { - Decreased air entry over left side on chest } \\
\text { auscultation revealed, corresponding to } \\
\text { CXR finding of left lower zone collapse }\end{array}$ & $\begin{array}{l}\text { - TS culture: commensals only } \\
\text { - ETA: EV/RV PCR positive, scanty growth } \\
\text { of alpha-haemolytic streptococci, negative } \\
\text { fungal smear and culture } \\
\text { - BAL: PCP, bacterial, AFB and fungal smear } \\
\text { and culture all negative. Mycoplasma, } \\
\text { Legionella, CMV, HSV PCR all negative } \\
\text { - Urine for Legionella Ag negative }\end{array}$ & $\begin{array}{l}\text { - Sedated, intubated and } \\
\text { ventilated } \\
\text { - IV piperacillin-tazobactam and } \\
\text { levofloxacin }\end{array}$ \\
\hline
\end{tabular}

Day 11 - Increased paradoxical breathing movement on weaning down sedation, also developed AFP with, hypotonia and paralysis of four limbs. Jerks still present with downgoing plantars. Sensation could not be tested as child was too weak to communicate

Day 12

- Working diagnosis was ATM affecting cervical cord C3-C6 levels. LP was performed with no evidence of NMO, MS or GBS

- Subsequently established definitive diagnosis of EV-D68-associated AFP on day 30

\section{- Normal CK}

- Urgent sagittal T2-weighted MRI spine showed mild T2 hyperintensity with mild expansion within central portion of cervical cord (C3-C6). No intraspinal mass or collection could be seen. Overall features were suggestive of ATM

- $\mathrm{AChR}$ and anti-aquaporin-4 $4^{\dagger}$ negative

- Eye exam: no evidence of optic neuritis

- IgG and IgM of anti-gangliosides ${ }^{\ddagger}$ : negative

- LP showed normal CSF glucose and protein. TCC $100 \times 10^{6} / L$ with neutrophil predominance (80\%). CSF culture negative. EV, HSV, VZV all not detected

- CSF oligoclonal protein§ was negative and CSF IgG" level was unremarkable

- EV-D68 was not demonstrated in CSF sample and plasma/serum sample was not tested for EV-D68 PCR

- Repeated NPA, ETA and stool on day 30 remained positive for EV-D68 which then turned negative on day 55

Day 64 - Successfully discharged from PICU after 2 months' stay

- Able to achieve full neurological recovery with intensive training by physiotherapists

Abbreviations: $\mathrm{AChR}=$ anti-acetylcholine receptor; $\mathrm{AFB}=$ acid-fast bacilli; $\mathrm{AFP}=$ acute flaccid paralysis; $\mathrm{Ag}=$ antigen; $\mathrm{ATM}=$ acute transverse myelitis;

$\mathrm{BAL}=$ broncho-alveolar lavage; $\mathrm{CBC}=$ complete blood count; $\mathrm{CK}=$ creatine kinase; $\mathrm{CK}-\mathrm{MB}=$ creatine kinase in muscle/brain; $\mathrm{CMV}=\mathrm{cytomegalovirus;}$

CSF = cerebrospinal fluid; CXR = chest X-ray; ECHO = echocardiogram; ETA = endotracheal aspirate; EV = enterovirus; GBS = Guillain-Barré syndrome; GOPC = general out-patient clinic; HSV = herpes simplex virus; IgG = immunoglobulin G; IgM = immunoglobulin M; IV = intravenous; IVIG = intravenous immunoglobulin; LP = lumbar puncture; LRFT = liver and renal function tests; MFS = Miller-Fisher syndrome; MND = motor neuron disease; $\mathrm{MP}=$ methylprednisolone; $\mathrm{MRI}=$ magnetic resonance imaging; $\mathrm{MS}=$ multiple sclerosis; $\mathrm{NMO}=$ neuromyelitis optica; $\mathrm{NPA}=$ nasopharyngeal aspirate; $\mathrm{PCP}=$ pneumocystis pneumonia (jiroveci); PCR = polymerase chain reaction; PICU = paediatric intensive care unit; $\mathrm{RD}=$ respiratory distress; RNA = ribonucleic acid; RT-PCR = reverse transcriptase-polymerase chain reaction; $\mathrm{RV}=$ rhinovirus; TCC = total cell count; TPE = therapeutic plasma exchange; $T S=$ throat swab; $\vee B G=$ venous blood gas; $V Z V=$ varicella-zoster virus

Anti-aquaporin-4 is a sensitive and highly specific serum marker of $\mathrm{NMO}$

Anti-ganglioside is panel used for diagnosis of motor neuropathies (GBS, MND, MFS, and multifocal motor neuropathies)

$\S$ CSF oligoclonal protein is positive in $80 \%$ of patients with MS

CSF IgG index is elevated in $80 \%$ of patients with MS 
The child was successfully discharged from the paediatric intensive care unit after 2 months (day 64) and achieved full neurological recovery with intensive training by physiotherapists. Subsequent review by a microbiologist using gene sequencing of initial specimens obtained on day 3 of admission to Queen Mary Hospital revealed EV-D68 RNA in nasopharyngeal aspirate, endotracheal aspirate and stool samples. Samples remained positive for 4 weeks (day 30, during acute deterioration warranting intensive care unit admission) and were negative after 6 weeks (day 55). The definitive diagnosis was EV-D68-associated acute flaccid paralysis (AFP) although EV-D68 was not present in the cerebrospinal fluid and plasma/serum samples were not tested for EV-D68 by RT-PCR.

\section{Discussion}

Acute flaccid paralysis is defined by the World Health Organization as a clinical syndrome of diverse aetiology characterised by acute-onset limb weakness or paralysis with varying degrees of autonomic and somatic nervous system dysfunction that reaches maximum severity over a period of days or weeks in a child younger than 15 years of age. ${ }^{1}$ It is a diagnosis of exclusion. In 1962, a new strain of EV, EV-D68, was identified in Berkeley, California. In 2014, EV-D68 outbreaks were reported in 20 countries including the United States, Canada, Europe, and Asia with a total of over 2000 cases. This corresponded to an increased global incidence of AFP. ${ }^{2}$ A casual association between EV-D68 and AFP is supported by Bradford Hill criteria. ${ }^{3}$ Despite public health attempts in 1988 to eliminate AFP through the Global Polio Eradication Initiative $\mathrm{e}^{4}$ and roll-out of the oral polio vaccine ${ }^{5}$ to prevent vaccine-associated poliomyelitis, the emergence of EV-D68-associated AFP has become a significant cause of neurological deficits in children since 2014. Owing to its impact on the healthcare system, a comprehensive literature review and further detailed studies are warranted. This is the first case encountered in our department. It is important for clinicians in Hong Kong to be alert for the disease.

As a newly emerging disease manifestation, a high index of suspicion and clinical awareness is advocated to facilitate earlier recognition and diagnosis through appropriate investigations, and presumably, improved clinical outcomes. The optimum treatment strategy has yet to be defined and preventive strategies are still being developed. Local and international notification systems as well as comprehensive surveillance are suggested since disease outbreaks may occur at any time and may have a serious impact on affected children.

\section{Author contributions}

Concept or design: WYK Chan, PL Ho.

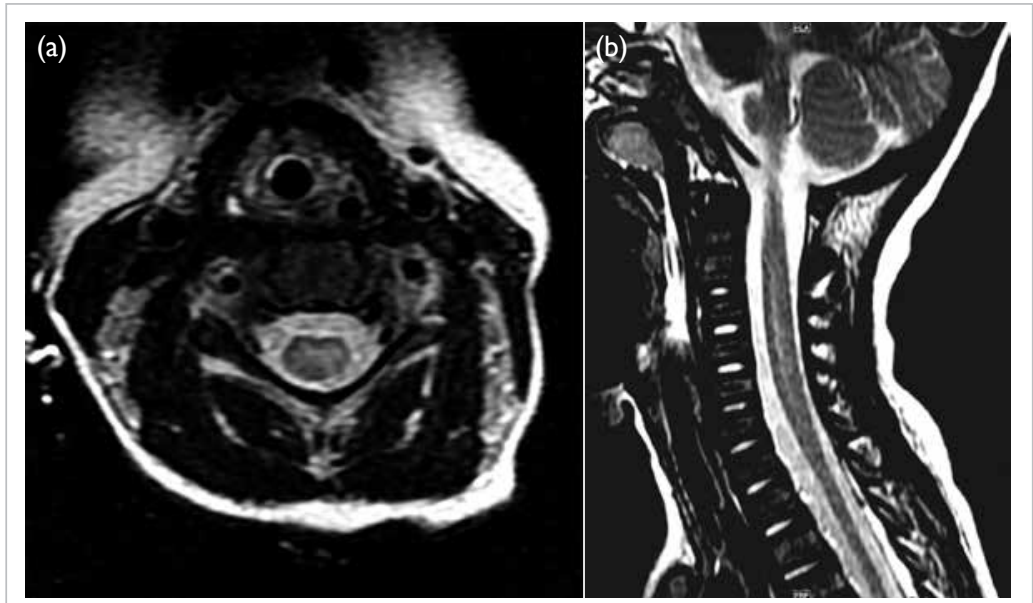

FIG. Axial (a) and sagittal (b) images on T2-weighted magnetic resonance imaging of spine showing mild T2 hyperintensity with mild expansion within central portion of cervical cord from $\mathrm{C} 3$ to $\mathrm{C} 6$

Acquisition of data: WYK Chan, SHY Chim, DML Tse.

Analysis or interpretation of data: WYK Chan, DML Tse, PL Ho.

Drafting of the manuscript: WYK Chan.

Critical revision of the manuscript for important intellectual content: All authors.

All authors had full access to the data, contributed to the study, approved the final version for publication, and take responsibility for its accuracy and integrity.

\section{Conflicts of interest}

All authors have disclosed no conflicts of interest.

\section{Funding/support}

This study received no specific grant from any funding agency in the public, commercial, or not-for-profit sectors.

\section{Ethics approval}

The parents of the patient gave consent for publication.

\section{References}

1. Bitnun A, Yeh EA. Acute flaccid paralysis and enteroviral infections. Curr Infect Dis Rep 2018;20:34.

2. Holm-Hansen CC, Midgley SE, Fischer TK. Global emergence of enterovirus D68: a systematic review. Lancet Infect Dis 2016;16:e64-75.

3. Messacar K, Asturias EJ, Hixon AM, et al. Enterovirus D68 and acute flaccid myelitis-evaluating the evidence for causality. Lancet Infect Dis 2018;18:e239-47.

4. World Health Organization. Global Polio Eradication Initiative. 2018. Available from: http://polioeradication. org/where-we-work/polio-endemic-countries/. Accessed 24 Mar 2018.

5. World Health Organization. Global Polio Eradication Initiative. Circulating vaccine-derived poliovirus. 2018. Available from: http://polioeradication.org/polio-today/ polio-now/this-week/circulating-vaccine-derivedpoliovirus/. Accessed 24 Mar 2018. 